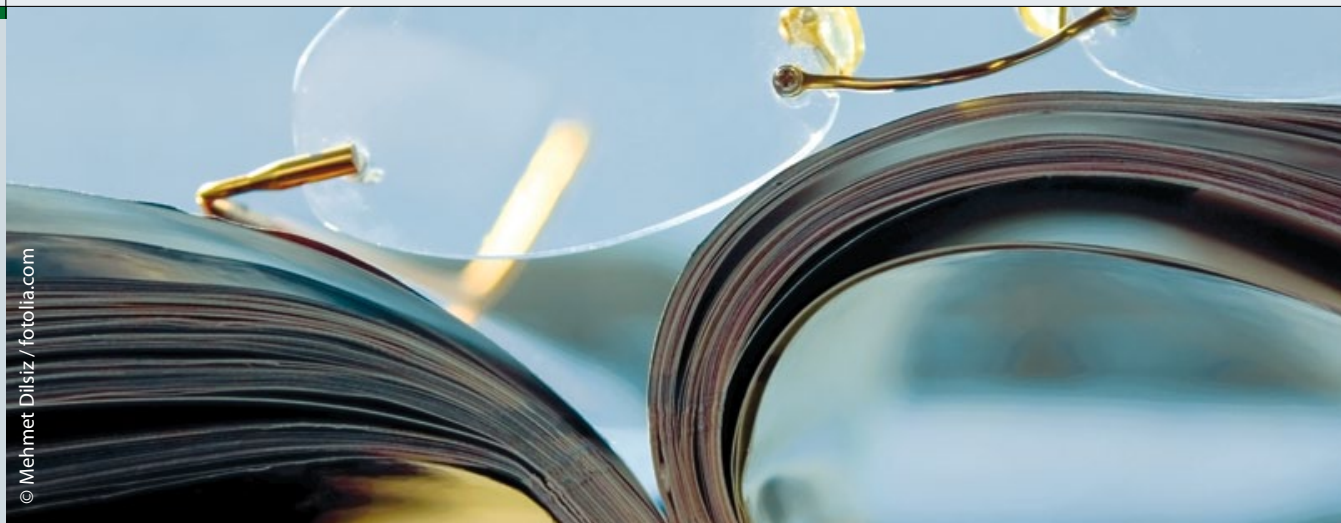

\section{Prostatakrebs-Diagnostik mit 5-alpha-Reduktasehemmern?}

\begin{abstract}
Männer mit einem Prostatakarzinom reagieren auf die Behandlung mit einem 5-alpha-Reduktasehemmer anders als Männer mit einem benignen Prostatasyndrom: Der PSA-Spiegel und das Prostatavolumen werden bei Männern mit Krebs weniger stark verringert als bei Männern mit der gutartigen Vergrößerung des Organs. Diese Befunde könnten diagnostisch genutzt werden.
\end{abstract}

n einer US-amerikanischen prospektiven Studie wurden 276 Männer untersucht, die einen permanent erhöhten PSA-Spiegel von mindestens $4 \mathrm{ng} / \mathrm{ml}$ oder einen Anstieg des PSA-Spiegels um 0,75

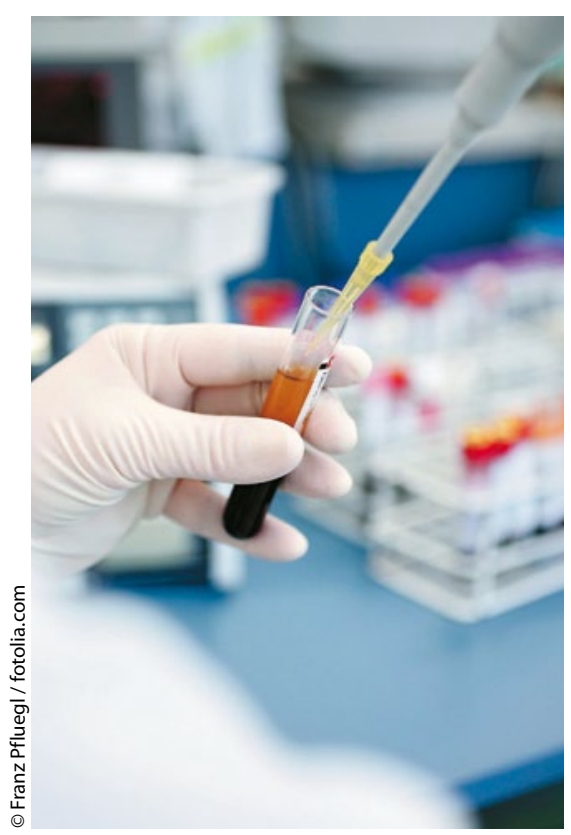

Möglicherweise lassen sich PSA-SpiegelVeränderungen nach Therapie mit einem 5-alpha-Reduktase-Hemmer für die Krebsdiagnostik nutzen. ng/ml pro Jahr hatten. Der Befund der digitalen rektalen Untersuchung war normal, und jeder Teilnehmer hatte bereits mindestens zwei negative Prostatabiopsien hinter sich. Im Studienzeitraum nahmen die Männner täglich 5 mg Finasterid oder 0,5 mg Dutasterid ein.

Die Studie hatte zwei Phasen. In der ersten Phase wurden sowohl das Prostatavolumen als auch der PSA-Spiegel sechs und zwölf Monate nach Beginn gemessen, und zwar bei 97 Patienten aus beiden Therapiegruppen. Ein Jahr nach Studienbeginn wurde bei diesen Männern eine Biopsie durchgeführt.

In der zweiten Studienphase mit 179 Patienten wurden nach mindestens einem halben Jahr Therapie mit dem einen oder anderen 5-alpha-Reduktasehemmer Biopsien vorgenommen, wenn sich der PSA-Wert nach Erreichen des Nadirs um mindestens $0,4 \mathrm{mg} / \mathrm{ml}$ verändert hatte. Sowohl Prostatavolumen als auch der PSA-Wert im Serum wurden in dieser Patientengruppe zu Beginn der Studie und nach einem Jahr gemessen.

In der ersten Studienphase stellte sich bei der Auswertung heraus, dass nach einem Jahr der PSA-Wert im Mittel um 2,4 ng/ml (46,7\%) und das Prostatavolumen um 7,1 $\mathrm{ml}(17,9 \%)$ abgenommen hatte. Bei 27 der insgesamt 97 Männer $(27,8 \%)$ wurde ein Prostatakarzinom (PCa) entdeckt. 16 der 27 Männer mit PCa hatten einen Gleason-Score von mindestens 7. Die mittlere Geschwindigkeit der PSA-Erhöhung lag bei 0,6 ng/mg pro Jahr. Veränderungen von mindestens 0,4 $\mathrm{ng} / \mathrm{ml}$ wurden als Kriterium für Biopsien in der nachfolgenden Studienphase gewertet.

In Phase 2 der Studie wurden bei 42 der 179 Männer (26,8\%) wiederholt Biopsien vorgenommen. 20 (76,9\%) der 26 Männer, bei denen damit ein PCa entdeckt wurde, hatten einen Gleason-Score von mindestens 7. Die PSA-Werte und das Prostatavolumen waren deutlich niedriger als bei den sechs Männern mit einem Gleason-Score von 6.

Fazit: Bei allen Männern unter Therapie mit 5-alpha-Reduktasehemmern wurde das Serum-PSA verringert. Bei Männern mit PCa war der Grad der Reduktion signifikant niedriger als bei Patienten mit einem benignen Prostatasyndrom (BPS). Die unterschiedlichen Reaktionen auf die Therapie könnten künftig bei der Unterscheidung zwischen PCa und BPS helfen. Derzeit ist jedoch noch unklar, ob die Therapie mit einem 5-alpha-ReduktaseHemmer die Entdeckung klinisch signifikanter Tumoren verbessert oder ob sie möglicherweise zur Progression der Krebserkrankung beiträgt. Peter Leiner

Kaplan SA et al. Prostate Biopsy in Response to a Change in Nadir Prostate Specific Antigen of $0.4 \mathrm{ng} / \mathrm{ml}$ after Treatment with 5-Reductase Inhibitors Markedly Enhances the Detection Rate of Prostate Cancer. J Urol 2012; 188: 757-61 